\title{
The impact of sexual activity during the third trimester of pregnancy on labor outcome in nulliparous women
}

\author{
Janice H. Simo ${ }^{1 *}$, Pascal Foumane ${ }^{2}$, Ngo Um E. Meka ${ }^{2}$, Julius S. Dohbit ${ }^{2}$, Felix Essiben ${ }^{2}$, \\ Emile T. Mboudou ${ }^{2}$
}

${ }^{1}$ Faculty of Health Sciences, University des Montagnes-Bangangté, Yaoundé, Cameroon
${ }^{2}$ Faculty of Biomedical Sciences, University of Yaoundé I, Yaoundé, Cameroon

Received: 16 February 2018

Accepted: 17 March 2018

*Correspondence:

Dr. Janice H. Simo,

E-mail: csimojanice@yahoo.com

Copyright: (C) the author(s), publisher and licensee Medip Academy. This is an open-access article distributed under the terms of the Creative Commons Attribution Non-Commercial License, which permits unrestricted non-commercial use, distribution, and reproduction in any medium, provided the original work is properly cited.

\begin{abstract}
Background: In the environment, there's not enough studies on the effects of sexual activity during pregnancy on labor outcome, especially for nulliparous women. The aim was to assess the effects of sexual activity during the third term of pregnancy on the outcome of labor in nulliparous women.

Methods: A prospective cohort study on labor was carried out for 11 months at the labor ward of the Yaoundé gynaeco-obstetric and pediatric Hospital. In this study compared women were exposed to at least one unprotected sexual intercourse with vaginal ejaculation per week during the third trimester of pregnancy (exposed group), to those who had less than one unprotected sexual intercourse per week (non-exposed group).

Results: Of the 1123 primiparous women who gave birth within the study period, 426 consented to enroll in the study. Amongst these women, 186 women in the exposed group compared to 240 women in the non-exposed group. Intercourse during pregnancy predisposed on arrival into the labor ward to a Bishop's score $\geq 7(\mathrm{RR}=1.94 ; \mathrm{CI}=1.63$ $2.3)$ and within the course of labor to a spontaneous per vaginal delivery $(\mathrm{RR}=1.18 ; \mathrm{CI}=1.06-1.31)$ and an active phase duration $<6$ hours $(\mathrm{RR}=1.52$; $\mathrm{CI}=1.36-1.7)$. Furthermore, sexual intercourse during pregnancy protected against labor induction $(\mathrm{RR}=0.21 ; \mathrm{CI}=0.12-0.36)$, dystocia $(\mathrm{RR}=0.36 ; \mathrm{CI}=0.27-0.49)$, cesarean section $(\mathrm{RR}=$ $0.29 ; \mathrm{CI}=0.15-0.55)$, episiotomy $(\mathrm{RR}=0.56 ; \mathrm{CI}=0.36-0.87)$ and an Apgar score $<7$ at the first minute of birth ( $\mathrm{RR}$ $=0.31 ; \mathrm{CI}=0.14-0.7)$.

Conclusions: Sexual activity during pregnancy improves the prognosis of labor in primiparous women. In the absence of contraindications, consented unprotected heterosexual vaginal intercourse should be promoted in nulliparous women.
\end{abstract}

Keywords: Labor, Pregnancy, Prognosis, Vaginal coitus

\section{INTRODUCTION}

Pregnancy is a period of great physical and psychological changes in women; perceived differently by each couple. These physical changes bring about discomfort in the couple, which leads to a change in frequency and even the arrest of intercourse during pregnancy. ${ }^{1}$ The sympathetic signs of pregnancy such as nausea, vomiting, enlargement of the abdomen and fatigue lead to a decrease in libido. ${ }^{2}$ In nulliparas, the fear of the effects of intercourse on pregnancy is greater because they are going through their first pregnancy; especially the fear of having a miscarriage or to hurt the unborn baby. ${ }^{1}$ Equally, the partners of nulliparous women are doubly scared of hurting the mother and the unborn baby. ${ }^{2}$ Some cultural believes forbid intercourse during pregnancy for various reasons, while others do admit intercourse but only at the beginning of the pregnancy. ${ }^{2}$ 
Libido changes during pregnancy are very diverse. In $60 \%$ of cases, libido is conserved during pregnancy, decreased in $28 \%$ of cases and increased in $12 \%$ of cases. $^{2}$ As thus, intercourse frequency reduces as pregnancy goes forth. ${ }^{3}$ During a study carried out by Orji et al, they showed that coitus frequency was reduced during pregnancy by $40 \%$ in the first term, $8 \%$ in the second term and of $16 \%$ in the third term. ${ }^{2}$ Generally and most often, as pregnancy evolves, it is noticed that there's a reduction in attaining orgasm, in sexual satisfaction and an increase in painful coitus. ${ }^{3}$

It has been pointed out that parity influences labor. Assessing labor progression and evolution curves in women, it is noticed that labor is longer and slower in nulliparas and this influences labor outcome.,

Coitus has known effects on pregnancy. ${ }^{6}$ Intercourse before the due day may lead to: preterm delivery, antepartum hemorrhage in case of placenta previa, and rarely a pelvic inflammatory disease. ${ }^{3}$ At the end of pregnancy, breast and genitalia stimulation have been preconized as means to enable natural endogenous oxytocin release. ${ }^{7}$ Equally, the presence of the penis in the vagina during intercourse leads to vaginal stretching and stimulation of the cervix; as thus the Fergusson's oxytocin secretion reflex is observed. ${ }^{7}$ The semen ejaculated during intercourse in the vagina is rich in Prostaglandin E, considered as a means of accelerating cervical ripening. ${ }^{8}$ Endorphins and steroid hormones released during intercourse are considered as labor onset means. ${ }^{9}$ A study showed a link between the capacity of attaining orgasm during pregnancy and a shortened second phase of labor, a decrease in labor induction rate, a decrease in oxytocin use and instrumental delivery. ${ }^{6}$

It is assumed that there's a link between coitus in the third trimester of pregnancy and the mechanism of labor onset. $^{3}$ Foumane et al, in Yaoundé found out in a general population of women that, intercourse favoured spontaneous labor onset, improved cervical dilatation, reduced the duration of the active and delivery phases of labor, and favoured per vaginal delivery. ${ }^{10}$ These effects are not specifically applied to nulliparous women in whom labor is often more tedious. ${ }^{5}$ In available literature, most studies on sexual activity during pregnancy in nulliparous women focus on: the observation of this sexual activity, the physical and psychological changes during pregnancy, the relationship between the two partners, the analyses of intercourse and the inquiry of sexual satisfaction. Therefore, we sought to assess the impact of sexual intercourse during the third trimester of pregnancy on labor outcome in nulliparous women.

\section{METHODS}

A prospective cohort study on labor was carried out from the $1^{\text {st }}$ October 2015 to $31^{\text {st }}$ August 2016 at the labor ward of the Yaoundé gynaeco-obstetric and pediatric Hospital. The study included all nullipara who gave birth in the hospital within the study period and had consented to participate in the study. Women who were forbidden intercourse during pregnancy (patients with placenta previa or preterm labor), with twin pregnancy, AIDS patients, women who had doubts on their sexual activity during pregnancy and antepartum fetal death were excluded.

The study compared women exposed to at least one unprotected sexual intercourse with vaginal ejaculation per week during the third trimester of pregnancy (exposed group) against those who did not have at least one unprotected sexual intercourse per week (nonexposed group). Calculated, the minimal sample size was 158 nulliparous women per group.

A questionnaire made up of five parts was used to collect data. On arrival into the labor ward, the identification part of the questionnaire was filled. Then, the third and fourth parts of the questionnaire which concerned the status on arrival in the hospital and the progress of labor with regards to the partogram respectively were followed up and recorded. The last but not the least part of the questionnaire was filled with the parameters of the baby at birth. After delivery, when the women had already regained their hospitalization rooms, the second part which concerned the sexual frequencies and habits during pregnancy was filled and the women followed up till their hospital outing.

The impact of intercourse during the third term of pregnancy on labor outcome were identified by calculating relative risks and their confidence intervals at $95 \%$. The $\mathrm{p}$ value was calculated using the chi-squared test. Fisher's exact test was used to calculate the $p$ value when statistical conditions did not permit it. Student's test was used to compare means and when statistical conditions did not permit its use, the Wilcoxon Ranks' test was used. Labor progress curves were drawn by comparing the mean values of the different labor evaluation features (dilatation, station, effacement) at specific periods in each different group. The value of $\mathrm{p}<$ 0.05 indicating the existence of statistically significant differences or relationships was implemented. Database and statistical tests were carried out based on the software Epi info3.5.4 and OpenEpi 2.3.

\section{RESULTS}

Of the 1123 nulliparas who gave birth within this study period, the study sample consisted of 426 women who consented to enrolled in the study, 359 were excluded and 338 refused to talk about sex; giving a participation rate of $55.8 \%$. Sexual activity frequency throughout pregnancy in this study population sample is represented in Figure 1. The statistically significant sociodemographic and gynaeco-obstetric characteristics are shown in Table 1. Labor progression assessment features in the different groups are illustrated in Table 2 
and in the curves represented by Figure 2, 3 and 4. The baby's parameters are represented in Table 3.

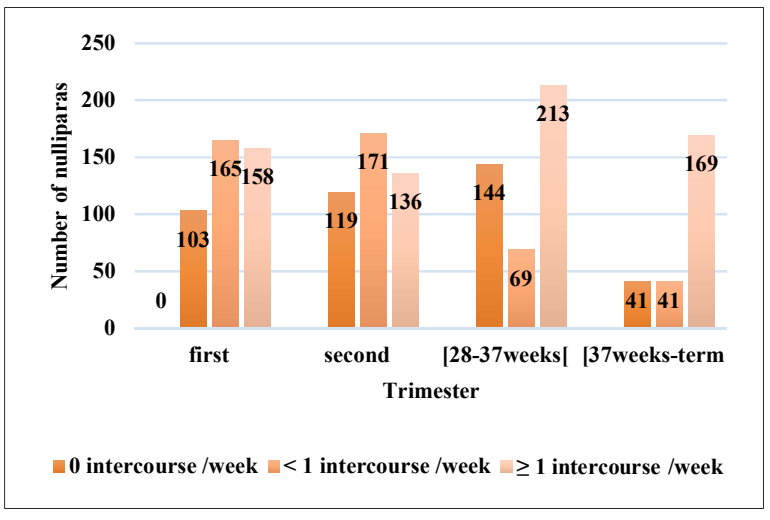

Figure 1: Frequency of sexual intercourse as pregnancy evolves.
As pregnancy evolves, the frequency of intercourse per week decreases in both groups of women. The study sample within the period (28-37 weeks and 37 weeks term) is reduced because 175 women gave birth within the $28^{\text {th }}$ and the $36^{\text {th }}$ week.

Most women in this study were single in both groups. The presence of dyspareunia was the most encountered feature of sexuality before pregnancy. About $32 \%$ of the women in the non-exposed group had lost their libido within the third term of pregnancy.

In this study, women who were exposed to at least one intercourse per week had a favourable Bishop's Score in about $78 \%$ of cases against $40 \%$ in the non-exposed. Also, $74.2 \%$ of women exposed to at least one intercourse per week on arrival in the labor ward in active phase of labor that is a dilatation $\geq 4 \mathrm{~cm}$ against $43.8 \%$ in the non-exposed.

Table 1: Sociodemographic and gyneco-obstetric characteristics in the exposed and non-exposed.

\begin{tabular}{|llllll|}
\hline Characteristic & Exposed, $\mathbf{n}(\%)$ & Non - exposed, $\mathbf{n}(\%)$ & OR & CI & p \\
\hline Married & $61(32.8)$ & $55(22.9)$ & 1.64 & $1.07-2.52$ & 0.015 \\
\hline Singled & $124(66.7)$ & $182(75.8)$ & 0.64 & $0.42-0.97$ & 0.024 \\
\hline Dyspareunia before pregnancy & $25(13.4)$ & $50(20.8)$ & 0.59 & $0.35-0.99$ & 0.024 \\
\hline Libido absent in the $3^{\text {rd }}$ term & $21(11.3)$ & $77(32.1)$ & 0.27 & $0.16-0.46$ & $<0.001$ \\
\hline${\text { Libido conserved in the } 3^{\text {rd }} \text { term }}^{72(38.7)}$ & $57(23.8)$ & 2.02 & $1.33-3.08$ & 0.001 \\
\hline
\end{tabular}

Table 2: Status of women in both groups on arrival in the labor ward.

\begin{tabular}{|llllll|}
\hline Characteristic & Exposed, $\mathbf{n}(\%)$ & Non-exposed, $\mathbf{n}(\%)$ & RR & CI & p \\
\hline Intact membranes & $166(89.2)$ & $157(65.4)$ & 1.36 & $1.23-1.52$ & $<0.001$ \\
\hline Clear amniotic liquor & $161(86.6)$ & $171(71.2)$ & 1.21 & $1.1-1.54$ & $<0.001$ \\
\hline Dilatation $\geq 4 \mathrm{~cm}$ & $138(74.2)$ & $105(43.8)$ & 3.7 & $2.43-5.6$ & $<0.001$ \\
\hline Station $\geq 0$ & $90(48.4)$ & $39(16.2)$ & 2.98 & $2.16-4.11$ & $<0.001$ \\
\hline Bishop's score $\geq 7$ & $144(77.4)$ & $96(40.0)$ & 1.94 & $1.63-2.3$ & $<0.001$ \\
\hline Uterine contractions & $173(93.0)$ & $175(72.9)$ & 1.27 & $1.17-1.4$ & $<0.001$ \\
\hline
\end{tabular}

Table 3: Characteristics of labor in the two groups of women.

\begin{tabular}{|lllllll|}
\hline Characteristic & Exposed, $\mathbf{n}(\%)$ & Non-exposed, $\mathbf{n}(\%)$ & RR & CI & p \\
\hline Labor induction & $13(7.0)$ & $80(33.3)$ & 0.21 & $0.12-0.36$ & $<0.001$ \\
\hline Labor stimulation & $39(21.0)$ & $112(46.7)$ & 0.45 & $0.33-0.61$ & $<0.001$ \\
\hline Labor induction indication & & & & & \\
\hline Premature membrane rupture & $12(6.5)$ & $49(20.4)$ & 0.31 & $0.17-0.58$ & $<0.001$ \\
\hline Post date & $4(2.2)$ & $17(7.1)$ & 0.31 & $0.1-0.88$ & 0.015 \\
\hline Dystocia & & & & & \\
\hline Dystocia during labor & $37(19.9)$ & $132(55.0)$ & 0.36 & $0.27-0.49$ & $<0.001$ \\
\hline Dynamic dystocia & $33(17.7)$ & $124(51.7)$ & 0.34 & $0.25-0.48$ & $<0.001$ \\
\hline Cervix dystocia & $2(1.1)$ & $34(14.2)$ & 0.07 & $0.02-0.31$ & $<0.001$ \\
\hline
\end{tabular}

More than a half of the women of the non-exposed group had dystocia within the course of labor compared to less than a quarter of the women in the exposed group. The difference between the two groups was statistically significant. In this study, having at least one unprotected intercourse per week favours per vaginal delivery and reduces complications linked to this lately. 
All data are not shown, but those statistically significant are represented in the Table 4.

Comparing the progress of dilatation curves in both groups, we realize that the dilatations of women exposed to coitus are far better throughout labor compared to the non-exposed women.
The Figure 3 show the progress of the means of the Bishop's score in nulliparous women of both groups. In this study notice that on arrival the mean of the exposed women is better than the non-exposed. Furthermore, throughout labor, the means of the Bishop's score in exposed women are better than that of the non-exposed nulliparas.

Table 4: Characteristics of delivery and Apgar's Score at the first minute of birth.

\begin{tabular}{|llllll|}
\hline Characteristic & Exposed, n (\%) & Non-exposed, n (\%) & RR & CI & p \\
\hline Delivery mode & & & & \\
\hline Cesarean section & $10(5.4)$ & $45(18.7)$ & 0.29 & $0.15-0.55$ & $<0.001$ \\
\hline Per vaginal & $176(94.6)$ & $195(81.3)$ & 3.49 & $1.81-6.73$ & $<0.001$ \\
\hline Description of per vaginal delivery & & & & \\
\hline Spontaneous delivery & $151(85.8)$ & $142(72.8)$ & 1.18 & $1.06-1.31$ & 0.001 \\
\hline Delivery with instruments & $25(14.2)$ & $53(27.2)$ & 0.85 & $0.76-0.94$ & 0.004 \\
\hline Episiotomy & $25(14.2)$ & $49(25.1)$ & 0.56 & $0.36-0.87$ & 0.006 \\
\hline Duration of the different labor phases & & & & & \\
\hline Active phase $<6$ hours & $169(95.5)$ & $122(62.9)$ & 1.52 & $1.36-1.7$ & $<0.001$ \\
\hline Active phase $\geq 6$ hours & $8(4.5)$ & $72(37.1)$ & 0.66 & $0.59-0.74$ & $<0.001$ \\
\hline Delivery phase $<30$ minutes & $174(98.9)$ & $152(77.9)$ & 1.26 & $1.17-1.36$ & $<0.001$ \\
\hline Delivery phase $\geq 30$ minutes & $2(1.1)$ & $43(22.1)$ & 0.05 & $0.01-0.21$ & $<0.001$ \\
\hline Complications of per vaginal delivery & & & & \\
\hline Complication present & $61(34.7)$ & $103(52.8)$ & 0.66 & $0.51-0.84$ & $<0.001$ \\
\hline Obstetrical trauma & $56(31.8)$ & $95(48.7)$ & 0.65 & $0.51-0.84$ & 0.001 \\
\hline Perineal tear & $41(23.3)$ & $69(35.4)$ & 0.65 & $0.47-0.91$ & 0.007 \\
\hline Vaginal tear & $12(6.8)$ & $26(13.3)$ & 0.51 & $0.27-0.98$ & 0.028 \\
\hline Apgar's Score $<7$ at $1^{\text {st }}$ birth minute & $7(3.8)$ & $29(12.1)$ & 0.31 & $0.14-0.7$ & 0.001 \\
\hline Apgar's Score $>7$ at $1^{\text {st }}$ birth minute & $179(96.2)$ & $211(87.9)$ & 1.1 & $1.04-1.02$ & 0.001 \\
\hline
\end{tabular}

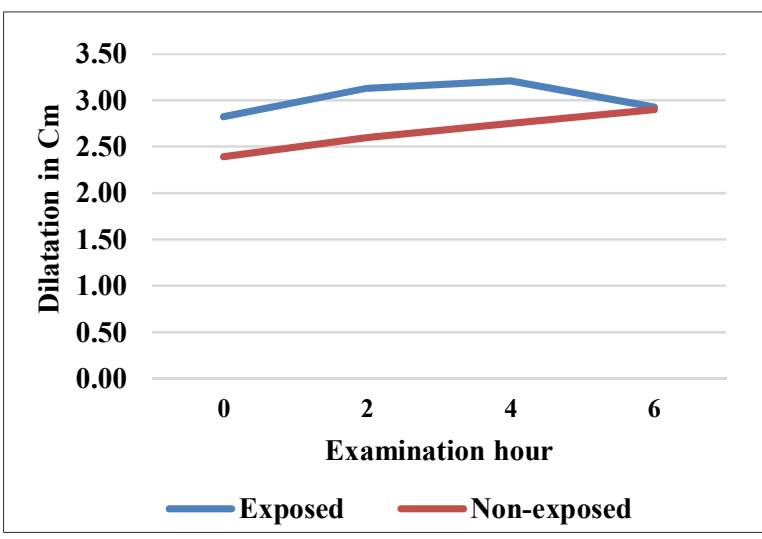

Figure 2: Evolution of the means of dilatation during labor in the two groups.

The Figure 4 outlines the mean of the frequency of uterine contractions every 10 minutes within the course of labor. In this study notice that these mean values remain better in the group of women exposed to at least one sexual intercourse per week during the third trimester of labor compared to the non-exposed women even though both groups of women are nulliparous.

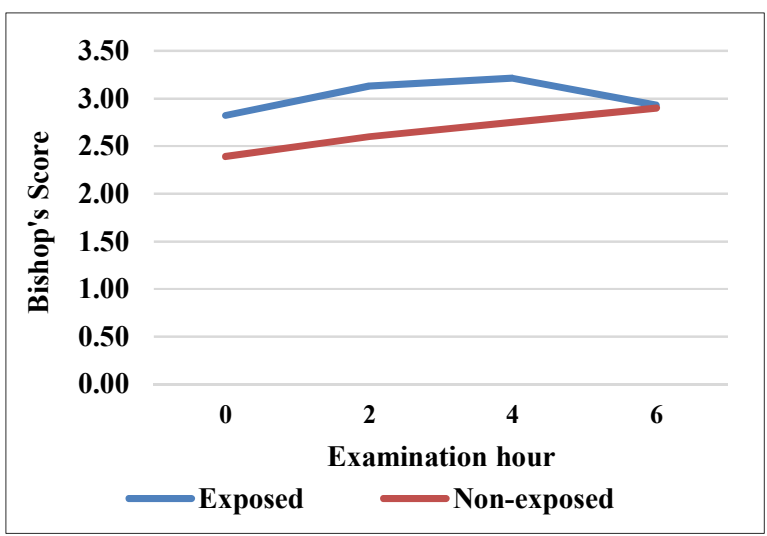

Figure 3: Evolution of the means of Bishop's score during labor in the two groups.

\section{DISCUSSION}

Women who were single, having dyspareunia before pregnancy and an absent libido in the third term of pregnancy were exposed to the practice of less than one intercourse per week. These because those singles don't always have their partners with them all the time; while 
those with dyspareunia due to the discomfort they experience during intercourse will not like to live such discomfort during pregnancy.

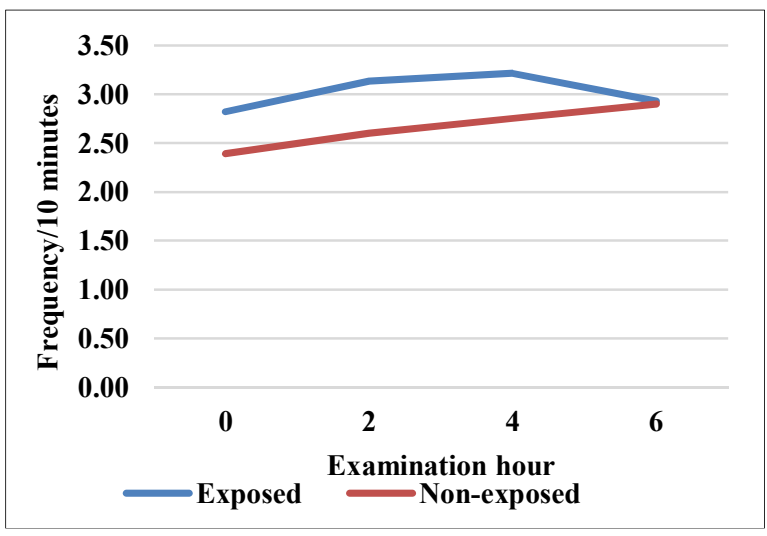

Figure 4: Evolution of the means of the frequency of uterine contractions during labor in the two groups.

In this study, sexual intercourse during pregnancy predisposed on arrival into the labor ward to intact membranes, a clear amniotic fluid during membrane rupture, a dilatation $\geq 4 \mathrm{~cm}$, a station $\geq 0$, a Bishop's score $\geq 7$ and the presence of uterine contractions. These results are similar to those found by Foumane et al, in a sample of women who were not specifically nulliparous. ${ }^{10}$ This findings show like Brustman et al, had shown, that uterine activity increases with coitus. ${ }^{11}$ In contrast to this study findings, are those of Schaffir who in a similar study like ours, found out that coitus was not associated with cervical ripening. ${ }^{12}$ The presence of Prostaglandin E in semen added to local mechanical stimulation of the cervix by the penis during intercourse might enable cervical ripening in primiparous women. ${ }^{8}$ Also, orgasm can be at the origin of uterine contractions. ${ }^{9}$ Equally, the presence of the penis in the vagina during intercourse leads to its distension and the excitation of the cervix, as thus initiating Fergusson's reflex by which oxytocin secretion is observed that stimulates the uterus. ${ }^{7}$

Sexual intercourse protects against labor induction, stimulation, premature membrane rupture, postdate delivery, dystocia within the course of labor especially dynamic and cervical dystocia and cesarean section. These results corroborate Foumane et al, results in Cameroonian women. ${ }^{10}$ This study results can equally be compared to those of Tan et al, who in a similar study concerning the effects of sexuality at term on the duration of gestation, labor induction and delivery mode, found a statistical difference on the reduction of postdate delivery, the duration of gestation and in the rate of labor induction. ${ }^{8,9,13}$ These could be explained by the presence of Prostaglandin E in semen, and the mechanical force that the penis exercises on the cervix during coitus might favor cervical maturation and protect nulliparous women from cervical dystocia. Also, orgasm and breast stimulation during intercourse lead to the release of oxytocin. ${ }^{8,13}$ The lately favors uterine contractions and avoids dynamic dystocia.

According to Zhang et al, the normal duration of active phase of labor is 5.5 hours in primiparas; meanwhile the delivery stage lasts 30 minutes in primiparous women. ${ }^{4}$ In this study, sexual activity during the third trimester of pregnancy was associated with spontaneous per vaginal delivery without instrumental delivery and even episiotomy, an active phase $<6$ hours, a delivery phase $<30$ minutes and a delivery without obstetrical trauma especially perineal and vaginal tear. These results are similar to those found by Foumane et al, in a population of women who were not specifically primiparous. They concluded that coitus at term of pregnancy favored per vaginal delivery and reduced the duration of the active phase and the delivery stage. These authors had not noticed a statistically significant difference in the two groups for obstetrical trauma. This difference in this study could be explained by the fact that their study was carried out in a study population mostly made up of multiparous in whom obstetrical trauma during delivery is reduced.

Finally, sexual intercourse during the third trimester of pregnancy protects against an Apgar score $>7$ at the first minute of birth. In contrast to this-findings are those of Foumane et al, in their study in which they did not observe any difference in the Apgar score at the first minute of birth in the group of women exposed and not exposed to intercourse during the third term of pregnancy. This could be explained by the fact that a reduced active phase and delivery stage durations in exposed women in this study leads to a better Apgar score at birth in women exposed to intercourse.

However, these results should be taken with some caution, as many other confusion factors might introduce bias and misinterpretation of this study results.

\section{CONCLUSION}

The frequency of sexual intercourse reduces as pregnancy evolves. The presence of dyspareunia before pregnancy and the absence of libido during the third term of pregnancy were factors associated with the practice of less than one intercourse per week in the nulliparas. Having at least one intercourse per week during the third term of pregnancy in nulliparous women exposes to a dilatation $\geq 4 \mathrm{~cm}$, a station $\geq 0$, a Bishop's score $\geq 7$, intact membranes and the presence effective uterine contractions on arrival in the labor ward; spontaneous per vaginal delivery, an active phase of labor of duration $>6$ hours and a delivery stage duration $>30$ minutes.

Furthermore, sexual activity during the third term of pregnancy protects nulliparous against labor induction and stimulation, premature membrane rupture, postdate delivery, dystocia during labor, caesarean section, instrumental delivery, episiotomy and obstetrical trauma 
especially perineal and vaginal tear and an Apgar score $>$ 7 at the first minute of birth.

Funding: No funding sources Conflict of interest: None declared

Ethical approval: The study was approved by the Institutional Ethics Committee

\section{REFERENCES}

1. Babazadeh R, Najmabadi KM, Mirzaii K, Masomi Z. Changes in sexual desire and activity during pregnancy among women in Shahroud, Iran. Int J Gynaecol Obstet. 2013;120(1):82-4.

2. Orji EO, Ogunlola IO, Fasubaa OB. Sexuality among pregnant women in South West Nigeria. J Obstet Gynaecol. 2002;22(2):166-8.

3. Jones C, Chan C, Farine D. Sex in pregnancy. Can Med Assoc J. 2011;183(7):815-8.

4. Zhang J, Troendle JF, Yancey MK. Reassessing the labor curve in nulliparous women. Am J Obstet Gynecol. 2002;187(4):824-8.

5. Neal JL, Lowe NK, Patrick TE, Cabbage LA, Corwin EJ. What is the slowest-yet-normal cervical dilation rate among nulliparous women with spontaneous labor onset? J Obstet Gynecol Neonatal Nurs. 2010;39(4):361-9.

6. Kontoyannis M, Katsetos C, Panagopoulos P. Sexual intercourse during pregnancy. Health Sci J. 2012;6(1):82-7.

7. Kavanagh J, Kelly AJ, Thomas J. Breast stimulation for cervical ripening and induction of labour. Cochrane Database Syst Rev. 2005;(3):CD003392.
8. Ben-Haroush A, Yogev Y, Bar J, Glickman H, Kaplan B, Hod M. Indicated labor induction with vaginal prostaglandin E2 increases the risk of cesarean section even in multiparous women with no previous caesarean section. J Perinat Med. 2004;32(1):31-6.

9. Tan PC, Yow CM, Omar SZ. Coitus and orgasm at term: effect on spontaneous labour and pregnancy outcome. Singapore Med J. 2009;50(11):1062-7.

10. Foumane P, Mboudou ET, Sama JD, Baba S, Enama Mbatsogo BA, Ngwana L. Sexual activity during pregnancy and prognosis of labor in Cameroonian women: a cohort study. J Matern-Fetal Neonatal. 2014;27(13):1305-8.

11. Brustman LE, Raptoulis $M$, Langer $O$, Anyaegbunam A, Merkatz IR. Changes in the pattern of uterine contractility in relationship to coitus during pregnancies at low and high risk for preterm labor. Obstet Gynecol. 1989;73(2):166-8.

12. Schaffir J. Sexual intercourse at term and onset of labor. Obstet Gynecol. 2006;107(6):1310-4.

13. Wagner NN, Butler JC, Sanders JP. Prematurity and orgasmic coitus during pregnancy: data on a small sample. Fertil Steril. 1976;27(8):911-5.

Cite this article as: Simo $\mathrm{JH}$, Foumane $\mathrm{P}$, Meka NUE, Dohbit JS, Essiben F, Mboudou ET. The impact of sexual activity during the third trimester of pregnancy on labor outcome in nulliparous women. Int J Reprod Contracept Obstet Gynecol 2020;9:1442-7. 